\title{
Influence of Joule-Annealing on Double-Peak GMI Effect in Co-Based Amorphous Ribbons
}

\author{
P. GAZDA*AND R. SZEWCZYK \\ Warsaw University of Technology, Institute of Metrology and Biomedical Engineering, \\ ul. Andrzeja Boboli 8, 02-525 Warsaw, Poland
}

\begin{abstract}
The results of optimizing the parameters of Co-based ribbons with different chemical composition are presented. The motivation for these studies is the construction of weak magnetic field sensors. The annealed ribbons show large impedance changes for saturating external magnetic field, and very large impedance change in the region of weak field. The highest GMI ratio of $506 \%$ was obtained for Joule-annealed $\mathrm{Co}_{70} \mathrm{Fe}_{5} \mathrm{Ni}_{2} \mathrm{Mo}_{5} \mathrm{~B}_{3} \mathrm{Si}_{15}$ sample. The paper also highlight the greatest dynamic of impedance changes around the local minimum for zero value of external field was observed for $\mathrm{Co}_{66} \mathrm{Fe}_{4} \mathrm{Ni}_{1} \mathrm{Si}_{15} \mathrm{~B}_{14}$.
\end{abstract}

DOI: 10.12693/APhysPolA.137.818

PACS/topics: Giant-magnetoimpedance, amorphous ribbon, magnetic field sensor

\section{Introduction}

The re-discovery of the Giant Magneto-Impedance (GMI) effect in $1994[1,2]$ created great hopes for magnetic field sensor design. GMI effect, observed the first in 1935 [3], is defined as a significant (gigantic) change in the impedance of the high frequency $\mathrm{AC}$ current conductor under the influence of a constant magnetic field. Theoretical predictions regarding impedance changes of $1000 \%$ [4] allow for the design of a high resolution sensor.

Since first GMI reports in soft magnetic microwires, intensive work on materials that have been shown ever greater impedance change, is still ongoing. However, there is only one commercial magnetic field sensor based on the GMI effect (Aichi Steel MGM-1DS). Nevertheless, numerous prototypes of sensors [5-15], and comparison of magnetic field sensors [16] show that this effect has huge application potential. The GMI sensor is characterized by a much higher resolution than GMR and Hall sensors, and comparable to Fluxgate sensors. It is possible to build a sensor for weak fields without the limitations of fluxgate sensors, such as limited miniaturization possibility and high energy consumption [16].

Over the years, GMI sensors have been developed with different operating principles. Some relied on the microprocessor processing of the characteristic curve [5-7], and the majority on the linear part of the impedance characteristic curve. The linear area occurs for the double peak GMI curve, between the zero $H_{0}$ field and the anisotropy field $H_{k}$. Directly measurement of weak fields using a linear part of the characteristic requires premagnetization [8]. It is possible to create a material with a linear characteristic above the $H_{k}$ anisotropy field, but this also requires additional biasing field [9]. There are

*corresponding author; e-mail: p.gazda@mchtr.pw.edu.pl solutions that avoid the problem of shifting characteristics by using $2 \mathrm{GMI}$ elements working in a differential system $[9,10]$. Another option to overcome the problem of pre-magnetization is to use the pick-up coil surrounding the GMI element connected to the phase-sensitive amplifier [11-13]. The characteristics of the induced voltage in the coil have the shape of the double peak GMI curve, but the characteristic for the negative half is symmetrical with respect to the point $(0,0)$, not to the axis OY. This allows to obtain a linear characteristic in the range $\left(-H_{k}, H_{k}\right)$.

The basic requirement for GMI materials is a high GMI factor and high sensitivity to applied constant magnetic field. Both of these parameters require high magnetic sensitivity. The most important impedance change is exhibited by materials with uniaxial magnetic anisotropy, perpendicular to the direction of DC field [17]. Such anisotropy, and improvement of the GMI ratio can be obtained by annealing in the magnetic field, or annealing under stress [17-19]. Due to Joule-annealing [20], the annealing occurs in the presence of transverse magnetic field induced by the current flow in the sample.

Optimization of materials properties is usually carried out in order to the highest GMI coefficient and linear characteristics at the largest possible area of magnetic fields. The authors of this article have focused on the optimization of material properties as well to obtain the sharpest GMI minimum for a zero external field.

\section{Experimental details}

The investigation were conducted using cobalt-based amorphous ribbons with composition of $\mathrm{Co}_{70} \mathrm{Fe}_{5} \mathrm{Ni}_{2} \mathrm{Mo}_{5} \mathrm{~B}_{3} \mathrm{Si}_{15}$ and $\mathrm{Co}_{66} \mathrm{Fe}_{4} \mathrm{Ni}_{1} \mathrm{Si}_{15} \mathrm{~B}_{14}$ with near zero magnetostriction, and $\mathrm{Co}_{84} \mathrm{Fe}_{1.5} \mathrm{Mo}_{2} \mathrm{Mn}_{1.5} \mathrm{Si}_{7} \mathrm{~B}_{2}$ characterized by significant negative magnetostriction $\left(\lambda_{s} \sim-12 \mathrm{ppm}\right)$. Ribbons were cut into samples with width $w=1 \mathrm{~mm}$ and lengths $l=60 \mathrm{~mm}$. The additional stresses induced in the samples due to the machining 
were relieved during the annealing procedures. The influence of a chosen method of improving GMI properties, namely Joule annealing, has been investigated. The process of Joule-annealing with currents ranging from 500 to $1100 \mathrm{~mA}$ with a step of $100 \mathrm{~mA}$ was carried out. For the alloy $\mathrm{Co}_{66} \mathrm{Fe}_{4} \mathrm{Ni}_{1} \mathrm{Si}_{15} \mathrm{~B}_{14}$, due to the best results obtained in the first annealing series, the annealing current was optimized by compacting the step to $25 \mathrm{~mA}$ in the range from 550 to $650 \mathrm{~mA}$. Real-time monitoring of ribbon resistance allowed to determine the moment of ribbon crystallization.

Research was carried out in the presence of 0 to $8 \mathrm{kA} / \mathrm{m}$ external field, for low and medium impedance test frequencies $(<10 \mathrm{MHz})$. To perform measurements special digitally controlled measurement system was developed, using Helmholtz coil as a source of homogenous DC magnetic field. Three pairs of perpendicularly set coils, supplied by 3 separated DC Power Supplies, with the application of a magnetoresistive sensor HMR 2300 as feedback, were used to compensate Earth's magnetic field. To apply an external magnetic field, with a flux's density of up to $8000 \mathrm{~A} / \mathrm{m}$, a bigger pair of coils supplied by a Rigol 831A Programmable Power Supply were used. In order to determine the exact field value, the value of the current flowing through the coils was measured, and then the field value was calculated from the Helmholtz coil constant. High frequency LCR bridge Microtest $6630 \mathrm{E}$ was utilized for measurement of the ribbon impedance with help of Kelvin probes. Special program for measurement system control and data acquisition was developed in National Instruments LabVIEW environment.

\section{Results and discussion}

The $Z(H)$ curves were measured for each of the produced samples. Figures 1-3 show the change of impendence as a function of the magnetizing field for selected samples. The coefficient of the impedance changes, otherwise known as the GMI coefficient, is defined as:

$$
\frac{\Delta Z}{Z}=\frac{Z(H)-Z\left(H_{\max }\right)}{Z\left(H_{\max }\right)} \times 100 \% \text {. }
$$

$\mathrm{Co}_{70} \mathrm{Fe}_{5} \mathrm{Ni}_{2} \mathrm{Mo}_{5} \mathrm{~B}_{3} \mathrm{Si}_{15}$ and $\mathrm{Co}_{84} \mathrm{Fe}_{1.5} \mathrm{Mo}_{2} \mathrm{Mn}_{1.5} \mathrm{Si}_{7} \mathrm{~B}_{2}$ alloys (Fig. 1 and 3) exhibited a single-peak character in the as-cast state. For all investigated ribbons, annealing process led to an increase in the GMI coefficient if the crystallization threshold was not exceeded. For $\mathrm{Co}_{70} \mathrm{Fe}_{5} \mathrm{Ni}_{2} \mathrm{Mo}_{5} \mathrm{~B}_{3} \mathrm{Si}_{15}$ samples annealing in the first stage resulted in a clear two-peak characteristic with $H_{k} \approx 300 \mathrm{~A} / \mathrm{m}$. Further increasing of annealing current led to an increase in the GMI coefficient, and a decrease in the anisotropy field up to annealing current value of $800 \mathrm{~mA}$, followed by a decrease in the GMI coefficient. The best results obtained were $506 \%$ impedance change. The biggest difference between the maximum value of GMI impedance and a local minimum at zero magnetization was $482 \%$, and the smallest observed anisotropy field $H_{k}$ was $101 \mathrm{~A} / \mathrm{m}$.

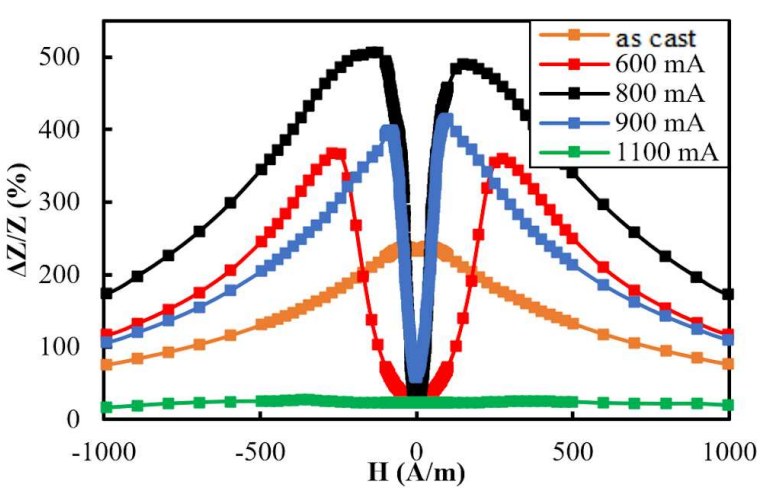

Fig. 1. GMI ratio in variation with $H$ for as-cast and Joule-annealed $\mathrm{Co}_{70} \mathrm{Fe}_{5} \mathrm{Ni}_{2} \mathrm{Mo}_{5} \mathrm{~B}_{3} \mathrm{Si}_{15}$ samples.

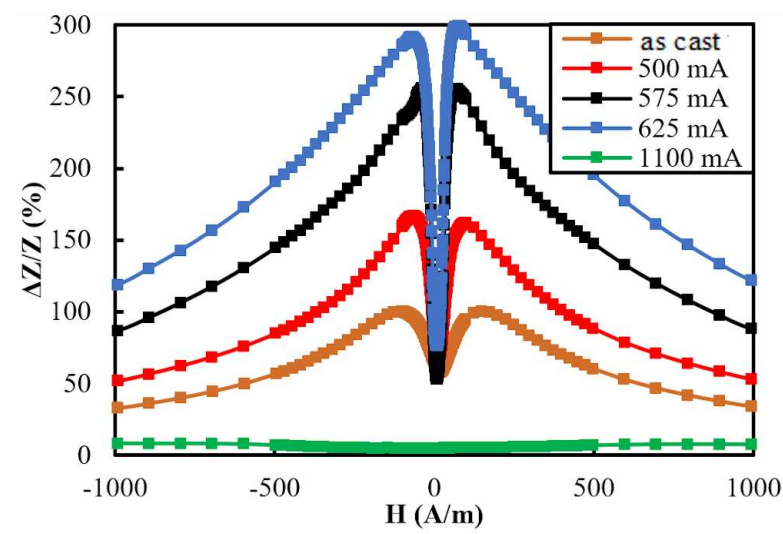

Fig. 2. GMI ratio in variation with $H$ for as-cast and Joule-annealed $\mathrm{Co}_{66} \mathrm{Fe}_{4} \mathrm{Ni}_{1} \mathrm{Si}_{15} \mathrm{~B}_{14}$ samples.

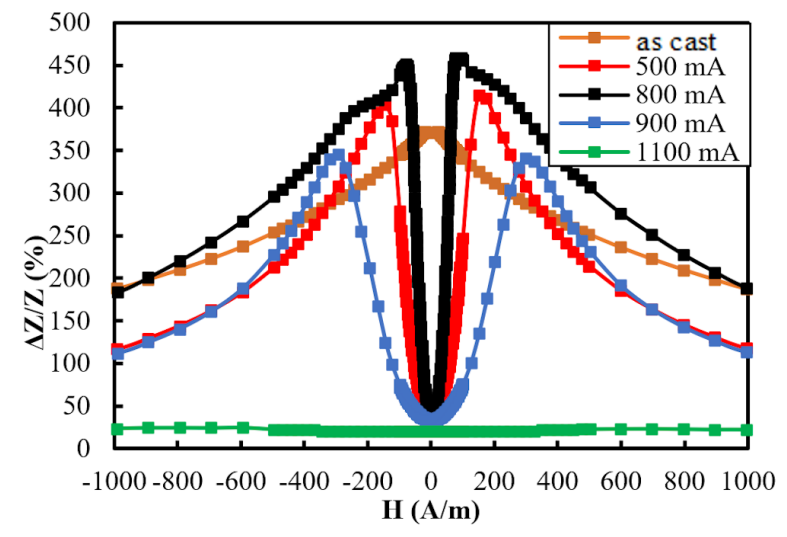

Fig. 3. GMI ratio in variation with $H$ for as-cast and Joule-annealed $\mathrm{Co}_{84} \mathrm{Fe}_{1.5} \mathrm{Mo}_{2} \mathrm{Mn}_{1.5} \mathrm{Si}_{7} \mathrm{~B}_{2}$ samples.

Samples made of $\mathrm{Co}_{84} \mathrm{Fe}_{1.5} \mathrm{Mo}_{2} \mathrm{Mn}_{1.5} \mathrm{Si}_{7} \mathrm{~B}_{2}$ ribbon showed much smaller changes than the other materials examined. The highest GMI coefficient for this alloy was $299 \%$. However, these samples also showed the smallest anisotropy field of about $75 \mathrm{~A} / \mathrm{m}$, and did not change significantly with annealing. The increase of the annealing current caused an increase in the maximum GMI, but also an increase in the local minimum value for the zero 


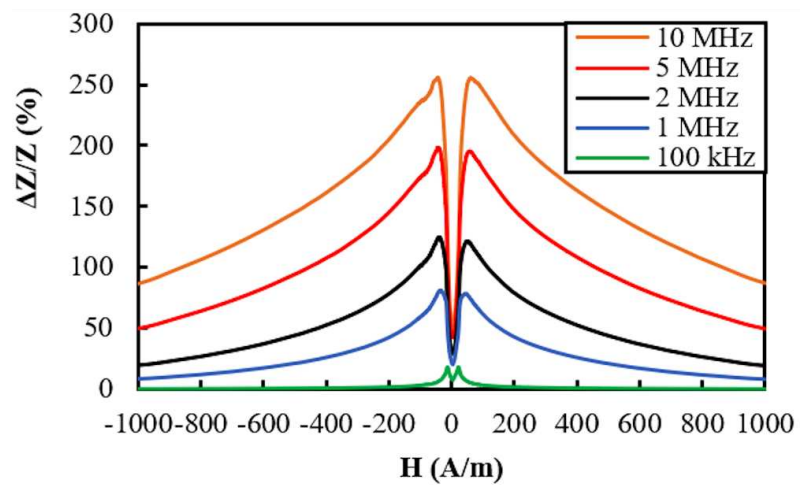

Fig. 4. GMI ratio in variation with $H$ for different frequencies for chosen $\mathrm{Co}_{66} \mathrm{Fe}_{4} \mathrm{Ni}_{1} \mathrm{Si}_{15} \mathrm{~B}_{14}$ sample.

field. Hence, the largest difference between the minimum for zero magnetization and the maximum of $202 \%$ was observed for the annealing current of $575 \mathrm{~mA}$. For this alloy there has been the greatest dynamics of impendance changes around the local minimum in "0".

It is widely believed that the highest GMI is achieved for samples with zero magnetostriction, therefore samples with high negative magnetostriction have been poorly studied. Our research has showed that the coefficient for such samples can be large, the maximum GMI value achieved for $\mathrm{Co}_{84} \mathrm{Fe}_{1.5} \mathrm{Mo}_{2} \mathrm{Mn}_{1.5} \mathrm{Si}_{7} \mathrm{~B}_{2}$ sample was $455 \%$. The largest change between the maximum and the local minimum at " 0 " was $435 \%$, while the value of the anisotropy field changed strongly, initially stabilizing at $175 \mathrm{~A} / \mathrm{m}$, decreasing to $95 \mathrm{~A} / \mathrm{m}$, and then growing again.

As part of the study we also investigated the influence of test frequency on the shape of the $Z(H)$ curve. The increase of frequency caused that the maximum GMI coefficient increased, while the local minimum value in " 0 " remained constant or changed insignificantly. An example of the dependence of the GMI characteristic on frequency is presented in Fig. 4. The frequency change did not have a significant impact on the value of the anisotropy field in the tested range.

\section{Conclusions}

The giant magneto-impedance (GMI) behavior of Joule-annealed cobalt-rich ribbons has been investigated. It was shown that annealed ribbons show significant impedance changes at full range of applied external magnetic field, and even very large impedance change in the region of weak field. The presented characteristics of Joule-annealed ribbons give opportunity to build sensor for large magnetic field based on decreasing GMI curve. In turn, in the narrow linear region between peak and local minimum, one allows to builtd a weak field sensor. Local GMI minimum at zero external field could also be used as null detector in compensation measurement techniques.

\section{Acknowledgments}

This work was financed from Statutory Funds of Institute of Metrology and Biomedical Engineering, Warsaw University of Technology.

\section{References}

[1] V. Panina, K. Mohri, Appl. Phys. Lett. 65, 1189 (1994).

[2] R.S. Beach, A.E. Berkowitz, Appl. Phys. Lett. 64, 3652 (1994)

[3] E.P. Harrison, G.L. Turney, H. Rowe, Nature 135, 961 (1935).

[4] J.M. Barandiaran, A. Garcia-Arribas, J.L. Munoz, G. Kurlyandskaya, IEEE Trans. Magn. 38, 3051 (2002).

[5] F. Pompéia, L.A.P. Gusmão, C.R.H. Barbosa, E.C. Monteiro, L.A.P. Gonçalves, F.L.A. Machado, in: Proc. of Joint Int. IMEKO TC1+TC7 Symposium, Ilmenau (Germany) 2005.

[6] Y. Jiang, J. Fang, P. Han, Y. Song, X. Huang, in: Proc. of Fifth Int. Symposium on Instrumentation Science and Technology, vol. 7133, Eds. J. Tan, X. Wen, SPIE, 2009, 71331L, p. 408.

[7] N. Horikoshi, S. Yabukami, Y. Murayama, T. Ozawa, K. Ishiyama, K.I. Arai, J. Magn. Soc. Jpn. 29, 472 (2005).

[8] A.A. Chlenova A.A. Moiseev, M.S. Derevyanko, A.V. Semirov, V.N. Lepalovsky, G.V. Kurlyandskaya, Sensors 17, 1900 (2017).

[9] R. Surla, N. Mitrović, S. Djukić, V. Ibrahimović, Serb. J. Electr. Eng. 13(3), 381 (2016).

[10] H. Hauser, L. Kraus, P Ripka., IEEE Instrum. Meas. Mag. 4, 28 (2001).

[11] B. Dufay, E. Portalier, S. Saez, C. Dolabdjian, D. Seddaoui, A. Yelon, D. Ménard, IEEE Trans. Magn. 53, 1 (2017).

[12] M. Malatek, P. Ripka, J. Electr. Eng. 57, 77 (2006).

[13] H. Chang, M. Yang, J. Liu, Y. Yu, in: Spring Congress on Engineering and Technology (S-CET), Xian (China) 2012, p. 1.

[14] G. Yu, X. Bu, B. Yang, Y. Li, C. Xiang, IEEE Sens. J. 11, 2273 (2011).

[15] S. Yabukami, H. Mawatari, N. Horikoshi, Y. Murayama, T. Ozawa, K. Ishiyama, K.I. Arai, J. Magn. Magn. Mater. 290-291, 1318 (2005).

[16] M.-H. Phan, H.-X. Peng, Prog. Mater. Sci. 53, 323 (2008).

[17] L. Kraus, Sens. Actuators A Phys. 106, 187 (2003).

[18] M. Knobel, K.R. Pirota, J. Magn. Magn. Mater. 242-245, 33 (2002).

[19] M. Varga, J. Marcin, M. Capik, D. Janickovic, P. Svec, I. Skorvanek, Acta Phys. Pol. A 128, 122 (2013).

[20] R. Gholamipour, A. Keyvanara, F. Shahri, S. Mirdamadi, J. Ultrafine Grained Nanostruct. Mater. 50, 111 (2017). 